\title{
THE SURGICAL TREATMENT OF CUSHING'S SYNDROME AND OTHER ADRENAL CORTICAL ABNORMALITIES
}

\author{
By Richard B. Welbourn, M.A., M.D., F.R.C.S. \\ Reader in Surgery, Queen's University, Belfast; Consultant Surgeon, Northern Ireland Hospitals Authority
}

Our understanding of the physiology and pathology of the adrenal cortex has increased greatly in recent years (Bayliss, I953, I955; Prunty, I956) and it is now possible to treat many of its disorders rationally, safely and effectively.

\section{Classification of Adrenal Cortical Disorders}

Lesions of the adrenals frequently cause disturbance of endocrine function. Various clinical syndromes may result, depending on whether the secretion is increased or diminished and, when it is increased, which hormones predominate. The lesions and syndromes may be classified as follows:

A. With Disturbance of Cortical Function

I. Increased Secretion:

Lesions:

(i) Hyperplasia.

(ii) Adenoma.

(iii) Carcinoma.

Syndromes:

Excess of-

Glucocorticoids causes Cushing's syndrome.

Androgens causes virilism (adreno-genital syndrome and some features of Cushing's syndrome).

Oestrogens causes feminization.

Electrocorticoids causes hyperaldosteronism (Conn's syndrome).

\section{Decreased Secretion:}

Lesions:

(i) Atrophy.

(ii) Destruction by haemorrhage, infarct, tuberculosis, metastatic carcinoma, etc.

(iii) Surgical removal.

Syndromes:

Chronic deficiency causes Addison's disease.

Acute deficiency causes acute adrenal failure (adrenal crisis).

B. Without Disturbance of Function

Lesions :

(i) Adenoma. (ii) Carcinoma.

(iii) Rare tumours, cysts, etc.

\section{Cushing's Syndrome}

This rather uncommon condition is caused in most cases by excessive secretion of adrenocortical hormones. This may be due either to an abnormality in the adrenals themselves or to an excessive production of corticotrophin (ACTH) by the anterior pituitary gland. It is often impossible to tell whether the adrenal or the pituitary is primarily at fault. An identical clinical picture may be produced by the prolonged therapeutic administration of cortisone (and its analogues) or corticotrophin.

\section{Causative Lesions}

(i) Adrenal. The adrenal glands may be (I) large (hyperplastic), (2) structurally normal, but with biochemical evidence of hyperfunction, or (3) the site of a tumour (adenoma or carcinoma). A tumour is the commonest finding in children, while large or normal glands are commoner in adults. Tumours are nearly always malignant in men, but often benign in women.

(ii) Pituitary. Occasionally the anterior pituitary gland is the seat of a basophil tumour, which secretes corticotrophin and stimulates the adrenal cortex. These tumours are nearly always small and do not cause pressure effects. The terms ' Cushing's disease ' or ' pituitary basophilism ' are applied to such cases. In others there may possibly be a functional disorder of the pituitary which results in excessive secretion of corticotrophin.

(iii) Other Causes. Cushing's syndrome is rarely associated with lesions of the hypothalamus, ovaries or liver or with carcinoma of the bronchus, thymus or pancreas (Thorne, 1952).

\section{Clinical Features (Fig. I)}

The average age of onset is about 30 , but the syndrome may develop at any time. Women are 
affected much more commonly than men. The clinical and metabolic features (Cushing, I932; Crooke, 1953; Cope and Raker, 1955) are best considered in relation to the known physiological effects of hydrocortisone, which is the most active of the glucocorticoids.

(I) Deposition of fat:

Obesity of face and trunk (increase in weight).

(2) Breakdown of protein:

Muscle wasting (lethargy and weakness).

Atrophy of skin (florid complexion, purple striae).

Osteoporosis (backache, spinal deformities, pathological fractures, hypercalciuria, urinary calculi).

Atrophy of capillary walls (purpura and bruising).

(3) Disordered carbohydrate metabolism:

Insulin-resistant diabetes mellitus.

(4) Inhibition of inflammatory reactions:

Severe infections.

(5) Disturbance of electrolyte metabolism:

Retention of sodium and chloride (arterial hypertension, oedema).

Excretion of potassium (hypokalaemic alkalosis).

(6) Changes in blood cells :

Polycythaemia (florid complexion).

Leucopenia (severe infections).

(7) Mental changes:

Psychosis.

(8) Virilization (amenorrhoea, hirsutism, darkening of the hair, acne, enlargement of clitoris). (When marked, this is probably the result of excessive secretion of androgens as well as glucocorticoids.)

Although there may be spontaneous partial remissions, the prognosis of the untreated disease is bad, half the patients dying within five years of its onset from the effects of hypertension, diabetes and infections.

\section{Diagnosis}

In a typical case the clinical, laboratory and radiological features which have been mentioned may establish the diagnosis, but direct evidence of adrenal cortical disorder should be sought. This may be done in two ways:

(I) Estimation of Urinary Steroids. The I7ketosteroid excretion (which is derived mainly from androgens) is raised in about half the cases, especially in those with signs of virilism. Very high levels almost always indicate a carcinoma. The excretion of glucocorticoids is nearly always raised above normal, especially after stimulation with corticotrophin. They may be estimated in the form of 17 -ketogenic steroids (Prunty,

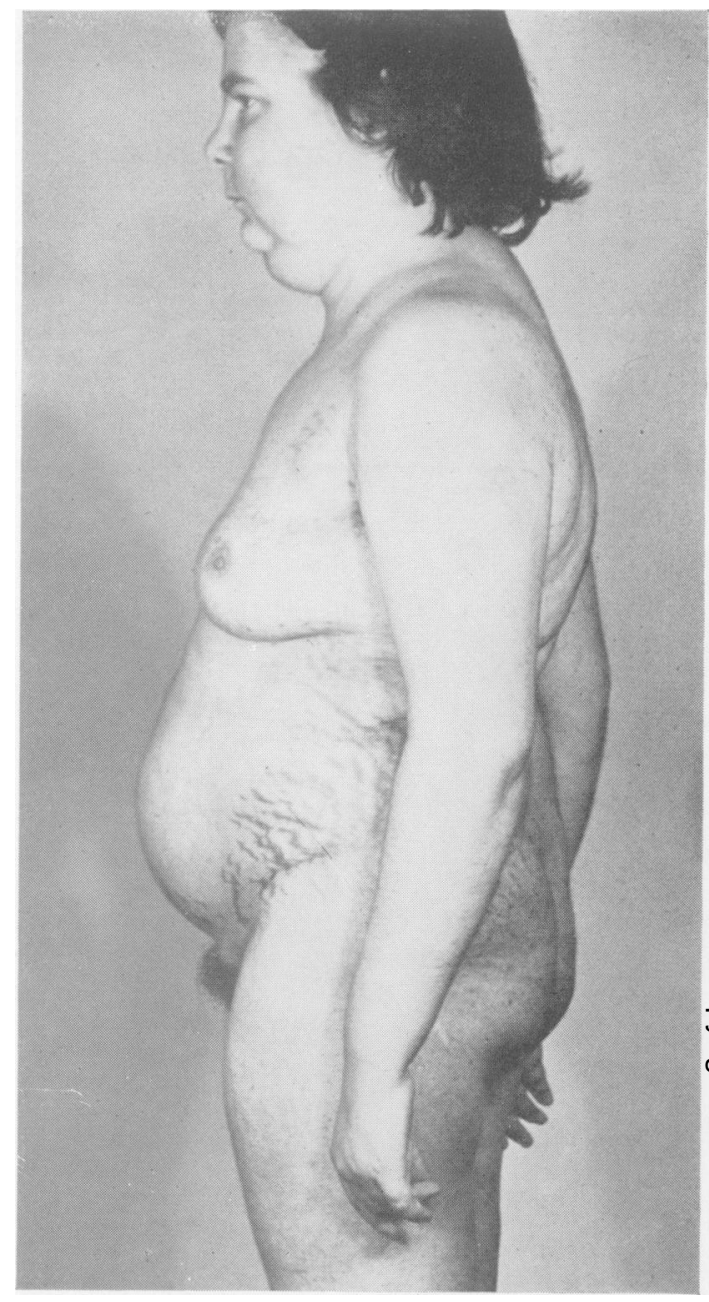

FIG. I.-Cushing's syndrome in a girl of 18 . Note the obesity of the face and trunk, the 'buffalo hump,' the abdominal striae and the kyphosis.

I956) or in various other ways. A method for distinguishing between benign (hyperfunction, hyperplasia or adenoma) and malignant (carcinoma) lesions has recently been introduced (Cope, 1956), which depends on the fact that $9 \alpha$-fluorohydrocortisone inhibits the formation of corticotrophin in much smaller doses than do cortisone, hydrocortisone or their other analogues. When this substance is given to patients with benign lesions there is a profound fall in the excretion of urinary steroids, while in carcinoma there is no fall since their secretions are not under corticotrophin control.

(2) Radiology. The adrenals may be outlined with oxygen, injected by the pre-sacral route, and can be visualized quite well in tomograms, especially if intravenous pyelography is performed 


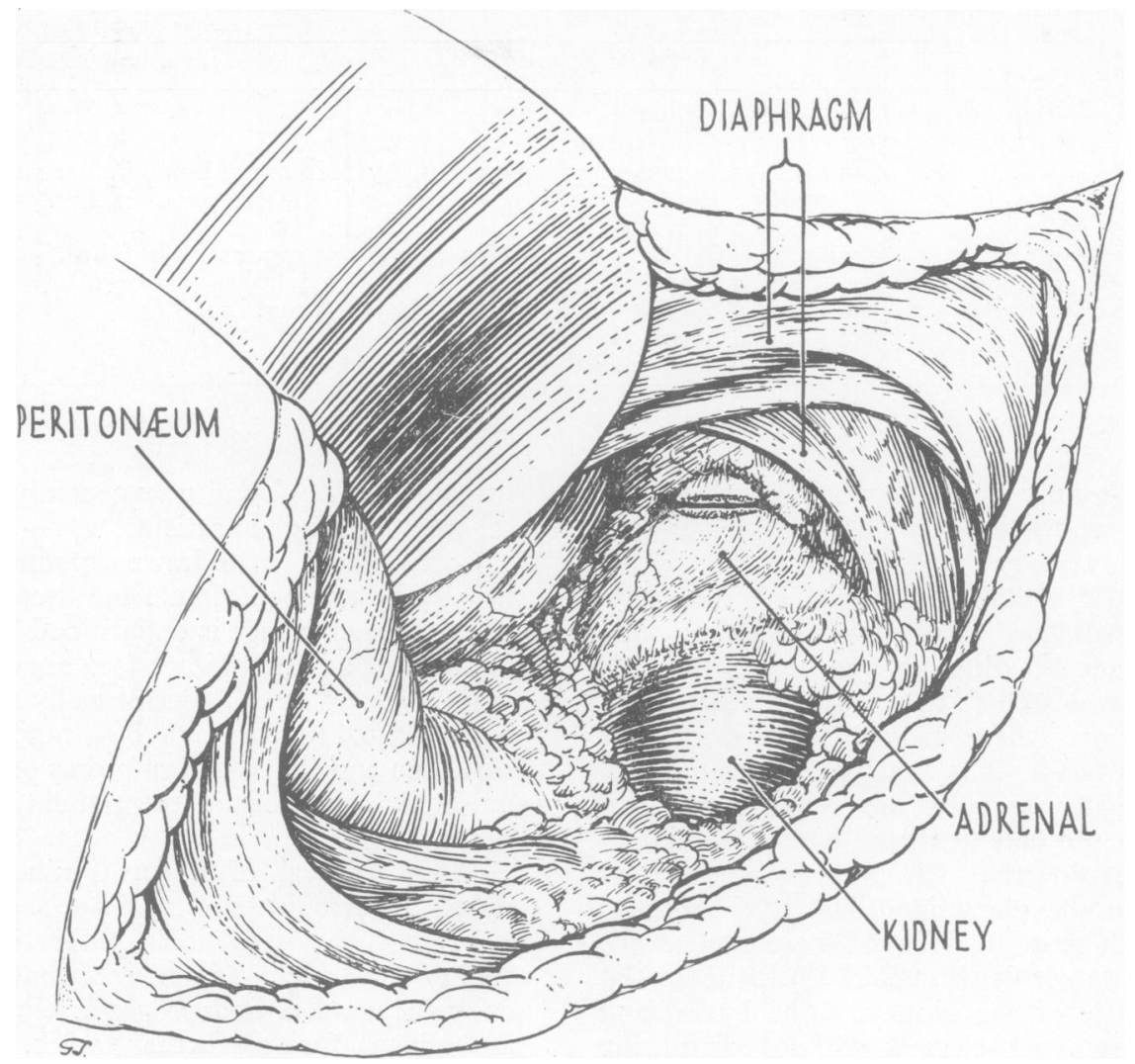

FIG. 2.-The crucial stage in left-sided sub-total adrenalectomy. The upper pole of the gland has been divided without disturbing its deep aspect.

at the same time (Steinbach et al., I952). This procedure will demonstrate gross hyperplasia and many tumours, but there is a large margin of error.

\section{TREatment}

The grave prognosis makes early treatment essential. Hypokalaemic alkalosis should be corrected by potassium chloride and infections must be controlled with antibiotics. If an adrenal tumour can be located it should be removed. In most cases, however, full investigation leaves doubt about the nature of the lesion, and surgical exploration of the adrenals is necessary. When the syndrome is caused by hyperplastic or hyperfunctioning glands adrenalectomy at present provides the best prospect of relief, although effective adrenocortical antagonists may one day render surgery unnecessary (Thorn et al., 1956).

Irradiation of the pituitary (Skrimshire, I955) and hypophysectomy are less satisfactory procedures and should be reserved for those very rare cases in which a pituitary tumour can be demonstrated.

The only point at issue is whether the adrenal resection should be sub-total or total. Sub-total removal produces a clinical remission in all cases and most of the patients require no cortisone replacement therapy after the first few months. A few, however, relapse later and require a further operation for removal of the remaining portion of gland. The effects of total adrenalectomy are probably more lasting, but permanent cortisone replacement is necessary and life is relatively precarious. Unless future experience shows that relapses are common, removal of nine-tenths of one gland and all of the other would seem to be the procedure of choice (Sprague et al., I953; Beck et al., 1954).

If no tumour has been located before operation the left gland is explored first, since it is the more accessible and the easier to resect sub-totally. When it has been exposed three courses are possible (Priestley et al., I95 I):

I. If a tumour is found, it is removed.

2. If the gland is atrophic it is probable (but not certain) that there is a tumour on the opposite side whose secretion is suppressing the production of corticotrophin. A biopsy is taken and the other gland explored later.

3. If the gland is normal or hyperplastic it is 


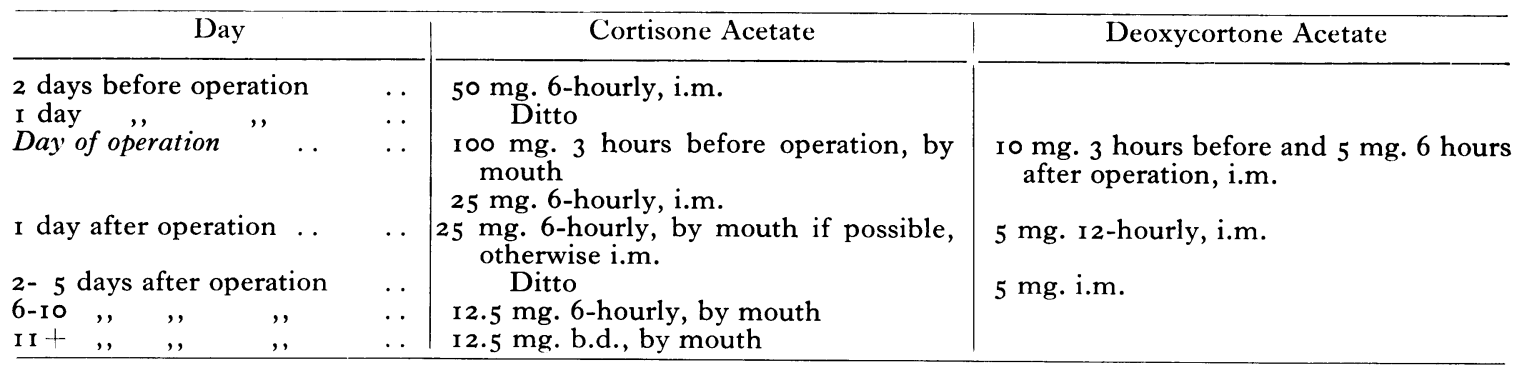

resected sub-totally and the whole of the other gland is removed later.

\section{Operative Technique}

The adrenals are relatively inaccessible surgically, and several different approaches to them have been advocated (Taylor, I953). In Cushing's syndrome, where gross obesity is often a complicating factor, it is best to operate on each gland separately and to use a postero-lateral incision with the patient in the lateral position.

On the left side the IIth rib is resected extrapleurally and the gland identified by its orange colour (which is quite different from that of the surrounding fat or of the tail of the pancreas) at the upper pole of the kidney. The lateral and anterior aspects are cleared without disturbing the gland posteriorly or injuring the small vessels which enter its periphery, and a small cornernot more than one-tenth of the whole-is selected to be left in the body. The upper pole is usually suitable and is severed from the main portion of the gland with scissors (Fig. 2). If it is viable its colour remains unchanged and blood oozes from its cut surface. If it is not viable the process is repeated with another corner. The remainder of the gland is then removed and the vein, which usually passes down from its medial aspect to the renal vein, is ligated and divided.

The right gland is best approached transpleurally through the bed of the Ioth rib, incising the diaphragm in the line of the skin incision. The gland is again located at the upper pole of the kidney and cleared of fat on its anterior aspect. The adrenal vein (or veins), which enter the vena cava directly, are seen clearly in the centre of the operation field and ligated and divided before the gland is removed.

\section{Substitution Therapy}

Cortisone has made adrenalectomy safe; without it the operation is usually fatal. Cortisone and deoxycortone (DOCA) must be given pre- and post-operatively and should be used for the first side as well as the second, since a functioning tumour may be found unexpectedly. The above scheme of dosage is satisfactory:-

Cortisone is withdrawn gradually and can usually be stopped after a few weeks or months. The required dosage is determined by the absence of signs of adrenal failure (see above) when trial reductions are made. Occasionally cortisone must be continued indefinitely. The necessity of taking cortisone and the early symptoms of its deficiency must be impressed on the patient, preferably in writing.

After removal of a functioning tumour the remaining atrophic adrenal tissue should be stimulated by the injection of corticotrophin-gel. Eighty units are given intramuscularly twicen daily for a week, and progressively smaller dosess are given for a further week. Substitution therapy is given as well.

\section{Adrenal Insufficiency}

Two types may be encountered (Beck et al., 1954):

I. Acute peripheral circulatory failure develops usually within 24 hours of operation and may appear very suddenly. So that it may be recognized and treated promptly an intravenous drip should always be started before operation and the blood pressure recorded every i 5 minutes after operation. The signs are tachycardia, hypotension and collapse. If the systolic blood pressure falls below $100 \mathrm{~mm}$. Hg. an intravenous infusion of hydrocortisone should be started immediately. I00 mg. (in $500 \mathrm{ml}$. of 5 per cent. glucose) are given in the first four hours, after which the rate is reduced. If the fall is profound or if it continues after starting hydrocortisone, nor-adrenaline should be given as well, using a 'two-bottle' transfusion set. A solution containing $4 \mathrm{mg}$. per $500 \mathrm{ml}$. of normal saline or 5 per cent. glucose is given as fast as necessary to restore the blood pressure. The response is usually immediate and the rate of infusion must be adjusted every few minutes. Withdrawal of nor-adrenaline must be slow.

2. The cortisone withdrawal syndrome develops 


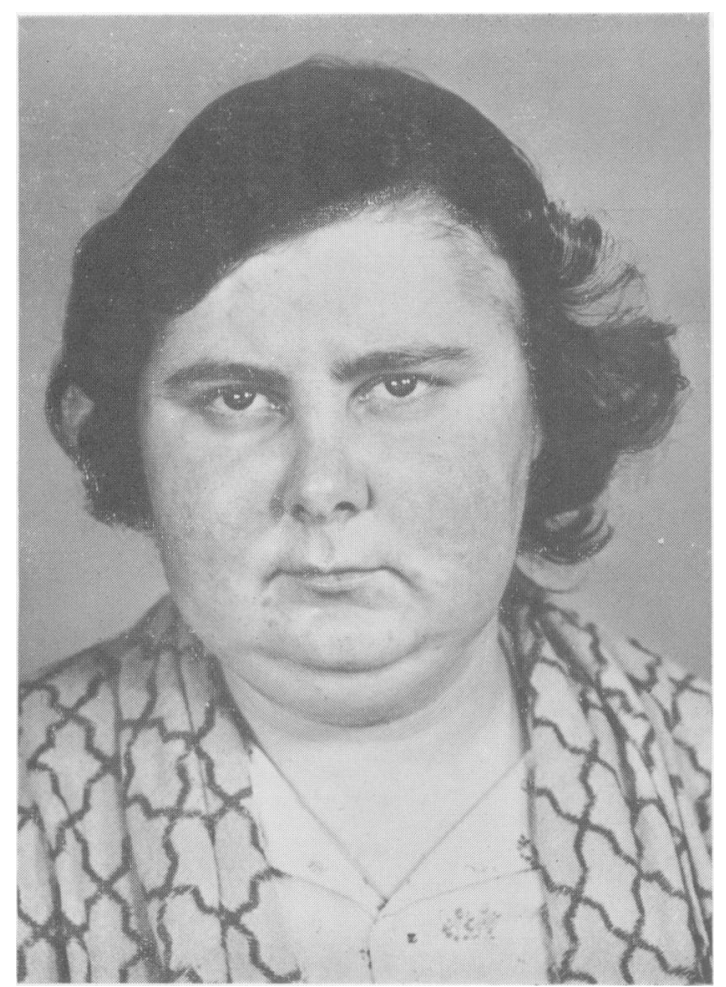

FIG. 3.-Cushing's syndrome. (Same patient as Fig. I.) Note the moon-shaped face and plethoric appearance.

if the cortisone dosage is reduced too rapidly after operation or if, as a result of stress, the patient's cortisone requirements increase. The first symptoms are early morning anorexia and nausea, aggravated by ambulation and eased by rest. The nausea becomes persistent and is followed by vomiting and dehydration. There is bodily weakness and a feeling of uneasiness or actual pain in the abdomen. The signs are tachycardia, an irregular low-grade fever and marked desquamation of the facial skin, followed later by hypotension, which may cause oliguria and anuria. Sometimes there are mental changes. The condition, which may be fatal if it is not treated, responds at once to an increase in the dose of cortisone or, if there is vomiting, to hydrocortisone given intravenously.

\section{Results of Surgical Therapy}

The immediate post-operative period may cause anxiety, but with proper care the operative mortality is low (one death in a personal series of 13 cases). Within a few weeks the appearance starts to return towards normal and the process is

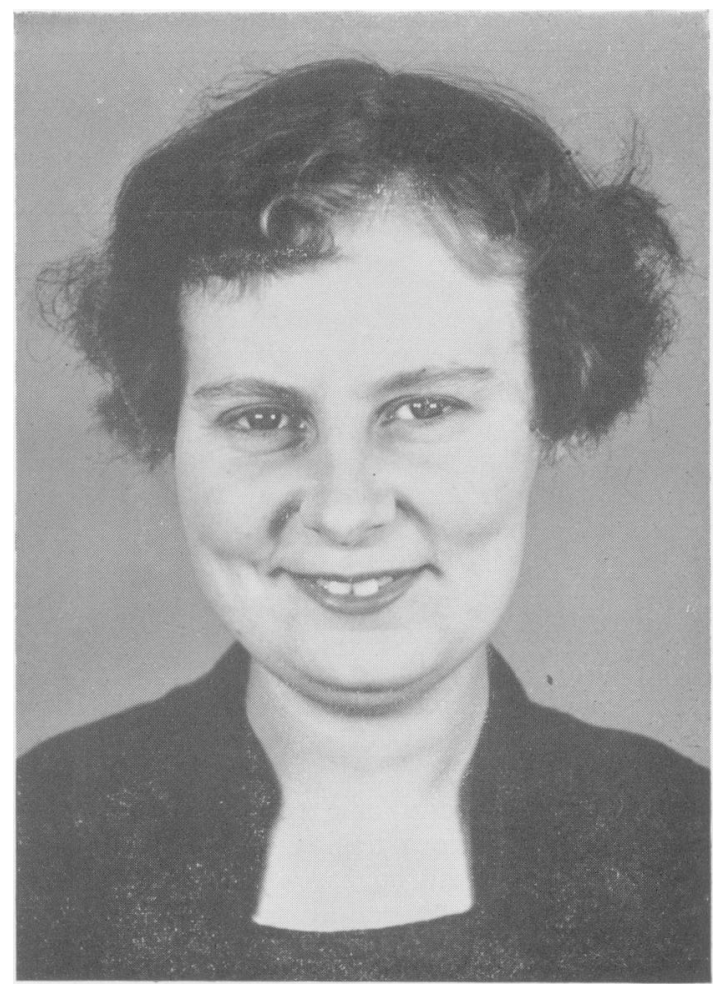

FIG. 4.-The same patient six months after sub-total adrenalectomy.

usually complete within about six months (Figs. 3 and 4 ). The skin of the face, and sometimes of the body, undergoes a fine scaly desquamation with itching, and this is accentuated if adrenal deficiency develops. Weight is lost, strength and energy are regained and a normal bodily configuration returns. Signs of virilism diminish, but rarely disappear completely. The hair becomes lighter and softer and sexual function is restored. (Sterility persists after destruction or removal of the pituitary.) The bones become re-calcified rather slowly and backache may persist longer than the other symptoms. Spinal deformities become stabilized. Brown pigmentation of the Addisonian type often develops temporarily in the operation scars and sometimes elsewhere. The blood pressure (both systolic and diastolic) falls significantly in all but returns to normal in only a few. Irreversible cardiovascular changes which were present before operation continue to endanger life, and the ultimate prognosis following surgery is not yet known. The early results, however, indicate that operation is well worthwhile (Sprague et al., r 953; Cope and Raker, I955). 


\begin{tabular}{l|l|c|c}
\multicolumn{1}{c|}{ Period } & \multicolumn{1}{c|}{ Lesion } & Male Syndrome & \multicolumn{1}{c}{ Female Syndrome } \\
\hdashline \begin{tabular}{l|l} 
Congenital \\
\hdashline Pre-pubertal
\end{tabular} & Usperplasia & $\begin{array}{c}\text { Macro-genitosomia praecox } \\
\text { ('Infant Hercules') }\end{array}$ & Female pscudo-hermaphroditism \\
\hline Post-pubertal & Hyperplasia or tumour & Excessive virilism & Virilism \\
\hline
\end{tabular}

\section{The Adreno-Genital Syndrome}

The adreno-genital syndrome (Broster, I939; Simpson, 1953) is a rare condition, which may be caused by a tumour or by hyperplasia of the adrenal cortex. The essential lesion in hyperplasia is probably biochemical and consists of a failure to synthesize hydrocortisone, excessive amounts of its precursor, I 7 -hydroxyprogesterone, being produced instead (Brit. med. $\mathcal{F}$., I955). This substance is androgenic and, unlike hydrocortisone, does not inhibit the production of corticotrophin by the pituitary. Consequently, there is hypersecretion of corticotrophin, hyperplasia of the adrenal cortex (affecting mainly the zona reticularis), excessive production of 17 hydroxyprogesterone and other androgens and deficiency of glucocorticoids.

The adrenal androgens, which are formed in neoplastic or hyperplastic glands, are responsible for the main clinical features of the syndrome. In some patients, especially those with tumours, there is an excess of glucocorticoids and these may cause some features of Cushing's syndrome. Forms intermediate between the two syndromes are not uncommon.

\section{Clinical Features}

The clinical picture varies with the age and sex of the patient, and the table above shows the main varieties:-

The androgens have three main effects:

I. Virilization (hirsutism, deeping of the voice, muscular development, increased libido and hypertrophy of the clitoris) (Fig. 5).

2. Regression of female characteristics (amenorrhoea, sterility, atrophy of the breasts, loss of subcutaneous fat and atrophy of the external genitalia (except the clitoris)).

3. Non-specific actions (protein synthesis, increase in weight, acne and occasionally fluid and salt retention and hypertension).

In children there is also precocious bodily growth and premature appearance and fusion of the epiphyses. The testes and prostate do not develop abnormally since there is no increased production of pituitary gonadotrophins. In the foetus the urogenital sinus may fail to differentiate into its urethral and lower vaginal components and at birth a female child may be mistaken for a male (Wilkins et al., 1955b).

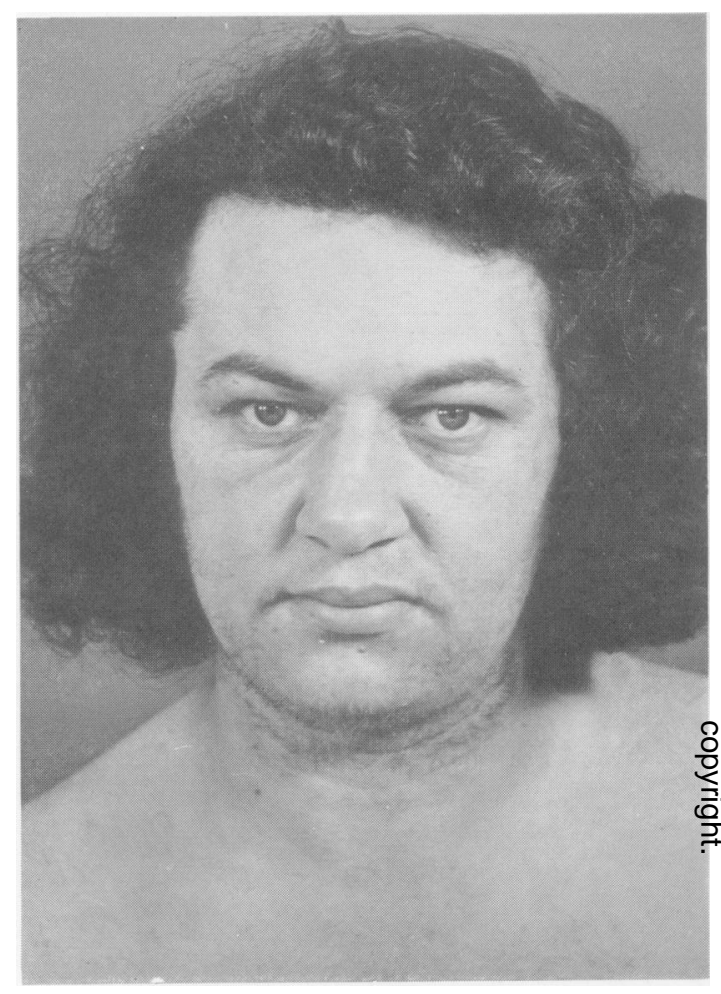

FIG. 5.-Adreno-genital syndrome in a woman of 30 . Note the hirsutism and general masculine appearance.

\section{DiagnOSIS}

The I7-ketosteroid excretion, which is nearly always raised, can be suppressed by cortisone in benign lesions, but not in carcinoma. In hyperplasia pregnanetriol (a metabolite of I7-hydroxyprogesterone) is found constantly in the urine, and $\subseteq$ in carcinoma there is often an excess of the androgen dehydroisonadrosterone. Radiographs of the adrenals may reveal hyperplasia or tumour. N In female pseudo-hermaphrodites endoscopy will reveal the presence of a uterine cervix and skin $\mathbb{N}$ biopsy will determine the 'chromosomal sex.' N

\section{Treatment}

The treatment depends on the nature of the $\frac{\mathscr{D}}{\mathbb{D}}$ adrenal lesion. A tumour requires surgical re- $\stackrel{\mathscr{C}}{\rightarrow}$ moval, while hyperplasia is treated with cortisone, 꿍 which inhibits the production of corticotrophin 
and supplies glucocorticoid (Wilkins et al., 1955a). Resection of hyperplastic adrenal tissue has yielded variable results in the past (Broster et al., 1953), but has now been largely abandoned. If the presence of a tumour cannot be excluded after full investigation, two courses are possible. If the condition is long-standing, a trial of cortisone therapy may be given for a few months. If the onset has been rapid, surgical exploration should be undertaken.

The results of treatment by removal of a tumour or by cortisone suppression depend on the age and development of the patient when treatment is started (Wilkins et al., r955a). In infants development becomes entirely normal. In older children abnormal development is checked and, in girls, female secondary sexual characters appear normally at puberty. In postpubertal girls and adults ovulation, menstruation and breast development occur within a few months, and pregnancy may become possible. If hirsutism is established its further progress is checked, but regression is usually slow and incomplete. The testes develop normally in boys. If the epiphyses have fused when treatment is started there can be no further skeletal growth. The blood pressure (when raised) is usually restored to normal.

When features of both Cushing's and the adreno-genital syndromes are present in the same patient, and there is no adrenal tumour, the nature of the change in protein metabolism should determine the form of treatment. Protein catabolism (Cushing's syndrome) indicates the need for adrenalectomy, while anabolism (adrenogenital syndrome) requires treatment with cortisone. If a tumour is present it should be removed, whatever form the clinical syndrome takes.

\section{Feminization in the Male}

This excessively rare syndrome is caused by an oestrogen-secreting carcinoma and the usual presenting feature is gynaecomastia. The tumour should be removed if possible (Wilkins, 1948).

\section{Primary Hyperaldosteronism (Conn's Syndrome)}

This rare condition, which has been recognized only recently, is caused by an adrenocortical adenoma, or occasionally carcinoma, which probably excretes excessive amounts of the electrocorticoid aldosterone (Conn, 1955; Lancet, 1956).

The clinical features are intermittent muscular pains, cramps, weakness and paralysis, polyuria and nocturia, hypertension and sometimes pinsand-needles and tetany. There is no oedema, but the reason for this is not clear. Investigation reveals albuminuria, hypokalaemia, mild hypernatraemia, alkalosis, an excess of potassium in the urine and inability of the kidney to secrete an acid urine after the administration of ammonium chloride. Aldosterone can be estimated only in special centres and an excess cannot always be recognized in the blood and urine. X-rays may show a tumour.

Treatment consists of correction of the potassium deficiency (which may cause a further rise in the blood pressure) and surgical removal of the tumour. Considerable improvement may be expected, but some features of the established disease are probably caused by nephrosclerosis and are irreversible.

\section{Adrenal Cortical Insufficiency in General Surgery}

Patients suffering from adrenal insufficiency are unable to respond normally to stress by the secretion of cortical steroids. If they suffer injury or infection or undergo even minor surgery they are likely to develop acute adrenal failure which may prove fatal. This state of affairs may be encountered in Addison's and Simmond's diseases, in virilizing adrenal hyperplasia, in patients who have previously been subjected to adrenalectomy or hypophysectomy, after the termination of cortisone or corticotrophin therapy, and in certain other conditions associated with toxaemia and malnutrition.

The clinical features of acute adrenal failure are similar to those which may follow adrenalectomy. The first sign may be severe prolonged hypotension following operation in a patient whose adrenal function has not previously been questioned. Adrenal failure should be suspected in such patients if there is no other obvious cause such as bleeding, dehydration, coronary thrombosis, pulmonary embolism or peritonitis.

Patients whose adrenal function is known to be potentially defective, and who require surgery, should be given supportive therapy in the same way as those undergoing adrenalectomy. If Addison's or Simmond's disease is suspected on clinical grounds, and time permits, adrenal cortical function should be fully investigated. If time is short, it is better to give supportive therapy than to withhold it. Those in whom adrenal failure is first suspected post-operatively must be treated immediately with hydrocortisone and (if necessary) nor-adrenaline intravenously and with cortisone and deoxycortone.

In conclusion it must be stressed that the problems of adrenal surgery cannot be shouldered by one man. They call for the closest co-operation between the general physician, the endocrinologist, the clinical bio-chemist, the radiologist and the surgeon.

Continued on page 28 


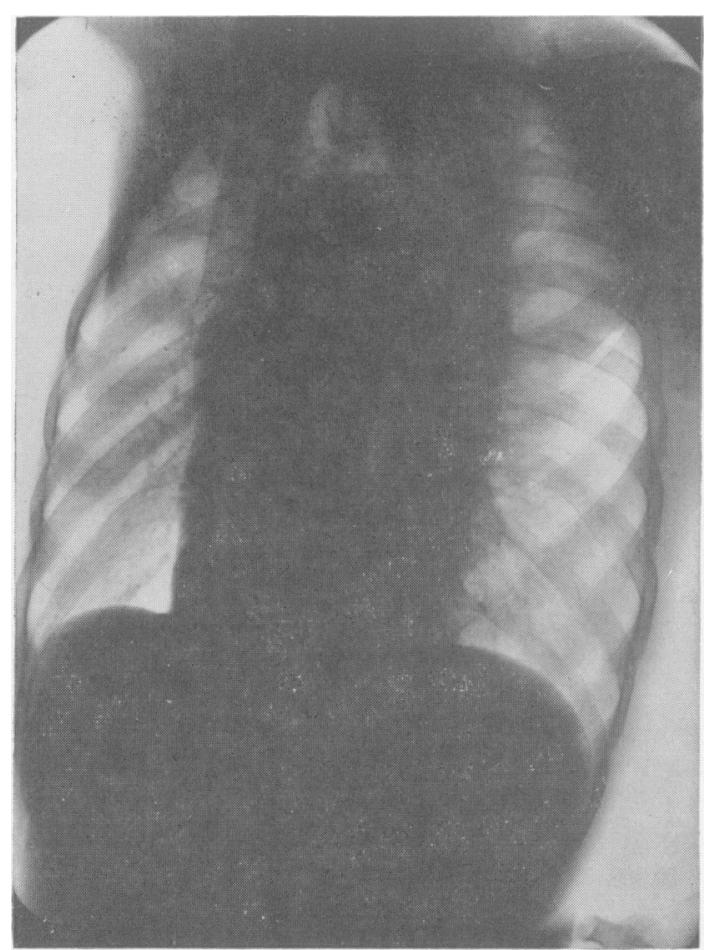

FIG. 3.- The barium can be seen entering the stomach through a grossly dilated cardia.

suffering from 'manic psychosis' but settled down on treatment and was discharged within a few months. There was no record of any abdominal or thoracic lesion or symptoms, and no history of difficulty in taking food or swallowing. For the past ten years or so he has had no difficulty in eating or drinking, his appetite has been good, and his bowel habit reasonably normal. He was admitted to hospital for investigation and Fig. 2 shows the result of a barium swallow. Fig. 3 is an oblique view. Oesophagoscopy revealed no ulceration of the oesophageal wall. During his short stay in hospital, he remained afebrile, had no complaints, and appeared to eat and drink quite normally.

\section{Comment}

This case is chiefly of interest because of the radiological appearances in the P.A. view of chest. Shanks, discussing this condition in its latter stages, states that a straight film of the chest may show an opacity emerging from the superior mediastinum spreading over and obscuring the right hilum to disappear behind the right border of the heart. In this case, the opacity continues practically in a straight line from the clavicle to the extreme base, and well to the right of the heart shadow. Ritvo shows a similar picture but observes that the extent of the change is not typical of cardiospasm. In the present case, the condition has undoubtedly been progressing for at least 36 years. There is no obstruction to the passage of food into the stomach, and there would appear to be no indications for surgical treatment.

\section{Acknowledgments}

I wish to thank Dr. J. W. Winchester for his help with the X-rays, and Mr. T. J. Wilmot, M.S., F.R.C.S., for the oesophagoscopy.

\section{BIBLIOGRAPHY}

SHANKS, S. COCHRANE, and KERLEY, P. (1950), 'A 'Textbook on X-ray Diagnosis,' Vol. 3, $4 \mathrm{I}$.

RI'TVO, M. (r956), 'Chest X-ray Diagnosis,' p. 334

Bibliography continued from page 21 , Richard B. Welbourn, M.A., M.D., F.R.C.S.

\section{BIBLIOGRAPHY}

BAYLISS, R. I. S. (1953), Postgrad. med. F., 29, 174.

BAYLISS, R. I. S. (1955), Brit. med. F., i, 495.

BECK, R. N., MONTGOMERY, D. A. D., and WELBOURN, R. B. (1954), Lancet, ii, I 140 .

Brit. med. F. (1955), ii, I491. Leading article.

BROSTER, L. R. (I939), Brit. F. Surg., 26, 925.

BROSTER, L. R., PATTERSON, J. and CAMBER, B. (I953), Brit. med. $\mathcal{F}$., ii, 1288 .

CONN, J. W. (1955), F. Lab. clin. Med., 45, 3.

COPE, C. L. (1956), Brit. med. F., ii, I93.

COPE, O., and RAKER, J. W. (1955), New Engl. F. Med., 253, 19.

CROOKE, A. C. (1953), Postgrad. med. F., 29, 179.

CUSHING, H. (1932), Bull., fohns Hopk. Hosp., 50, 137.

Lancet (1956), i, 141. Leading article.

PRIESTLEY, J. T., SPRAGUE, R. G., WALTERS, W., and SALASSA, R. M̈. (1951), Ann. Surg., 134, 464 .
PRUNTY, F. 'T. G. (1956), Brit. med. 7 ., ii, 615 and 673.

SIMPSON, L. (1953), Postgrad. med. F., 29, 184.

SKRIMSHIRE, J. F. P. (1955), Lancet, i, 270.

SPRAGUE, R. G., KVALE, W. F., and PRIESTLEY, J. T. (1953), F. Amer. med. Ass., 15i, 629.

STEINBACH, H. L., LYON, R. P., SMITH, D. R., and MILLER, E. R. (1952), Radiology, 59, 167

TAYLOR, S. (1953), Postgrad. med. F., 29, 208.

THORN, G. W RENOLD, A. E GOLDFIEN, A NELSON, D. H., REDDY, W. J., and HER'TZ, R. (1956), New Engl. F. Med., 254, 547 .

THORNE, M. G. (1952), Guy's Hosp. Rep., Ior, 25 I.

WILKINS, L. (1948), F. clin. Endocrinol., 8, I I I.

WILKINS, L., BONGIOVANNI, A. M., CLAYTON, G. W. GRUMBACH, M. M., and van WYK, J. J. (1955a), In 'The Human Adrenal Cortex,' p. 460 (Ciba Foundation), London.

WILKINS, L., GRUMBACH, M. M., van WYK, J. J., SHEPARD', 'T. H., and PAPADATỎ, C. (1955b), 'Pae diatrics,' 16,287 